\title{
Emotionality of pictures and the retention of related and unrelated phrases
}

\author{
THOMAS EVANS \\ Olivet College, Olivet, Michigan 49076 \\ and \\ M. RAY DENNY \\ Michigan State University, East Lansing, Michigan 48823
}

\begin{abstract}
College students were exposed once to a sequence of 12 picture-phrase combinations varying along two dimensions: emotionality of the picture and relatedness of the phrase to the picture. Retention of both pictures and phrases was tested after $24 \mathrm{~h}$. Emotional materials were recalled better than nonemotional; enhancement was greatest for pictures and greater for phrases related to pictures than for unrelated phrases. Relatedness was important for phrases, but not for pictures, suggesting that pictures cue verbal recall, but not vice versa. An extension of the encoding variability hypothesis was supported.
\end{abstract}

Research on the learning and retention of emotional verbal materials has a long and diverse history, but relatively few studies have shown definite results. A fair amount of research has been done to investigate the Freudian theory of repression, with mixed and often ambiguous results (Aborn, 1953; Erickson, 1938; Merrill, 1954; Zeller, 1950). More recently studies manipulating physiological and social variables have found evidence that emotionality enhances retention (e.g., Holmes \& Schallow, 1969). Results of verbal learning studies, however, have indicated that emotionality is not a relevant variable in verbal retention; that is, words that are defined or rated as emotional are not remembered any better than words that are not (Klugman, 1956; Kott, 1955; Weiner, 1966), even though the scaling of emotionality seems to be highly reliable (Koen, 1962; Underwood, 1966).

The failure of verbal learning studies to find consistent emotionality effects is puzzling, for there are clear theoretical reasons for expecting positive effects. Emotional enhancement can be predicted because of increased arousal during learning (Duffy, 1957), or because of deeper levels of processing which, logically and psychologically, would be expected for meaningful emotional materials (Craik \& Lockhart, 1972). Also, there is considerable evidence that encoding variability enhances free recall of a memory item (e.g., Melton \& Martin, 1972; Tzeng, 1973), presumably because more coded versions of the item are available during retrieval (Paivio, 1971). It seems reasonable that emotional arousal during processing of verbal materials would provide an additional distinctive code for storage. Why, then, have well controlled studies with reliable scaling of emotionality failed to produce consistent emotionality enhancement? It may be that these studies have failed to produce sufficient emotional arousal to activate the emotional code since the methods have usually involved presentation of serial lists of paired associate lists of single verbal items. Individual words obviously include evaluative or affective associations, but these effects are probably not sufficient to produce actual emotional arousal; that is, they are intellectual and semantic reactions rather than experiential reactions. Perhaps an emotional experience is necessary to activate the kind of emotional code which probably affects retention in our everyday lives. In searching for a method to produce this realistic emotional effect, we considered the use of pictorial materials.

One method that seemed promising involved the presentation of a picture with a verbal caption (Bahrick \& Gharrity, 1976). Their results indicate that pictorial information facilitates free recall of related but not unrelated verbal captions. This method seemed appropriate for the study of emotionality. It was reasoned that an emotional picture presented with a verbal phrase would elicit a more realistic emotional response than would a verbal phrase by itself or accompanied by a nonemotional picture.

On this premise, the present study examined the effects of pictorial emotionality on the retention of both pictures and phrases. Since Bahrick and Gharrity (1976) found pictorial facilitation for related but not unrelated verbal information, relatedness of the picture to the phrase was included in our experiment. Pictorial emotionality was crossed with picture-phrase relatedness in a 2 by 2 factorial design.

The variable encoding hypothesis applied to this design allows clear predictions for phrase recall: (1) Highest recall of phrases for the emotional-related (E-R) condition would be expected since three codes would 
be available (emotional, pictorial, and verbal); (2) intermediate levels of recall would be expected for the emotional-unrelated (E-U) and nonemotional-related (N-R) conditions, since two codes would be available [emotional and verbal or imaginal and verbal, respectively, with the assumption that imaginal coding of the verbal phrase would not occur in the unrelated conditions (Bahrick \& Gharrity, 1976)]; and (3) poorest recall would be expected for the nonemotional-unrelated condition since only the verbal code would be available.

Predictions concerning pictorial recall are less clear because it is not known whether picture-phrase relatedness facilitates pictorial recall. Although Paivio (1971) has argued that superior recall of pictures over verbal materials is due to dual coding (i.e., verbal coding of the pictures as well as imaginal), Nelson and Reed (1977) have found evidence that pictorial labeling is not automatic and that pictorial superiority does not depend on dual coding. If verbal coding of pictures does occur, then in this study the relatedness condition should facilitate picture as well as phrase recall, and the pattern of pictorial recall should follow the pattern of phrase recall. If not, only emotionality should affect pictorial recall; that is, recall for emotional pictures (two codes) should be superior to recall for nonemotional pictures (one code), regardless of the relatedness condition.

\section{METHOD}

\section{Subjects}

Thirty students were randomly selected from the subject pool of students enrolled in introductory psychology at Michigan State University. They were randomly assigned to two groups of 15 .

\section{Materials and Apparatus}

Fourteen pictures were cut from various magazines and newspapers and made into $14-\mathrm{mm}$ slides. Seven were subjectively rated as highly emotional, the other seven as emotionally neutral. To check these subjective ratings, the 14 slides were presented to a class of 30 upper-class students at Michigan State University. The students were instructed to rate the slides from 1 to 10 , with 10 being extremely emotional, and 1 being totally unemotional. Ratings for the seven emotional pictures ranged from 7.84 to 9.51 , while ratings for the nonemotional pictures ranged from 2.26 to 4.54 . In no instance were the emotional and nonemotional ratings even close to overlapping. Twelve phrases were constructed to go with the pictures so that each phrase that was presented with an emotional picture on List 1 could be presented with a nonemotional picture on List 2 . Thus, the two picture-phrase lists were constructed in such a way that the phrases were completely counterbalanced on the emotionality and relatedness variables. (To accomplish this, it was necessary to use one emotional and one nonemotional picture in List 2 which were not in List 1 ; i.e., Lists 1 and 2 had 12 identical phrases and 10 identical pictures. The 14 pictures and 12 phrases that were combined to create Lists 1 and 2 can be seen in Table 1.) Each list contained three emotional pictures with related phrases (E-R), three emotional pictures with unrelated phrases (E-U), three nonemotional pictures with related phrases (N-R), and three nonemotional pictures with unrelated phrases (N-U). Four presentation sequences were used for each list, so that all picture-phrase types occurred with approximately equal frequency in all positions, and thus order effects would be unlikely.

The slides were presented on a manually operated Kodak Carousel slide projector.

\section{Design}

A 2 by 2 by 2 repeated-measures design was employed, with emotionality of the pictures and relatedness of the picturephrase combination being the independent variables, and picture and phrase recall the dependent variables.

\section{Procedure}

Subjects were brought individually to a small room $(2.7 \mathrm{x}$ $5 \mathrm{~m}$ ). To maximize the effects of the emotionality variable and minimize rehearsal and other strategies (Estes \& DaPolito, 1967), incidental learning instructions were given as follows: "You will be shown a series of 12 pairs of pictures and phrases. You are simply to observe the picture-phrase pairs; we will discuss what you saw tomorrow."

The experimenter then presented the series of 12 pairs, showing each picture for approximately $1 \mathrm{sec}$, followed by the phrase for $1 \mathrm{sec}$, followed by a $3-\mathrm{sec}$ interval before the presentation of the next pair. At the end of the series, the subject was told that he was to return the next day to talk about the slides.

Table 1

Picture-Phrase Combinations, With Phrases Counterbalanced for Groups 1 and 2

\begin{tabular}{lll}
\hline \multicolumn{1}{c}{ Phrase } & \multicolumn{1}{c}{ Emotional Picture } & Nonemotional Picture \\
\hline See the baby & \multicolumn{1}{c}{ Related Picture-Phrase Condition } & \\
Food is important & Wounded Mother and Baby (2) & Woman and Baby (1) \\
Let's eat & Starving Child (2) & TV Dinner (1) \\
No more games & Sexy Seminude Eating Scene (2) & Family Restaurant (1) \\
Your turn to jump & Nude Couple Embracing (1) & Gambling Scene (2) \\
Dig another hole & View Atop a High Building (1) & Boys Jumping in Sand (2) \\
& Dead Soldier (1) & Tractor Digging (2) \\
Climb a tree & Unrelated Picture-Phrase Condition & \\
Radial tires are better & Sexy Eating Scene (1) & Family Restaurant (2) \\
Sailing is fun & Men Hanging (1) & TV Dinner (2) \\
It's raining & Starving Child (1) & Student at Blackboard (2) \\
There's a car & View Atop High Building (2) & Gambling Scene (1) \\
Pass the potatoes & Dead Soldier (2) & Boys Jumping (1) \\
\end{tabular}

Note-Subjects in Group 1 always saw an emotional picture with a particular phrase when subjects in Group 2 saw a nonemotional picture with that phrase and vice versa. 
The subject was firmly instructed that the project would be sabotaged if he were to discuss the slides with anyone before the next session.

When the subject returned the next day, the experimenter handed him a two-page test sheet. He was told not to work on the second page until the first was completed, and not to go back to the first page. Typewritten instructions on the top of the first page read: "Write down all the phrases that you can remember from yesterday's slide series. They needn't be exact." The instructions on the second page read: "Write a brief 5-10 word description of each picture that you can recall from yesterday's series." To make phrase recall comparable to the recall of picture descriptions, a phrase was scored as correct if at least two essential words were included from the original phrase that clearly identified the phrase. This procedure allowed for variations in sequencing of critical words and for leaving out or substituting unimportant words. Any ambiguous phrase was simply not scored as recalled. Picture descriptions were similarly scored as correct if at least two essential pictorial components were described that clearly identified the picture. The scoring was blind, and two independent judges showed agreement for all phrases and disagreed on three picture descriptions which were discarded.

\section{RESULTS AND DISCUSSION}

Mean recall per subject for pictures was 5.48 , compared with 4.20 for phrases. A Sandler A test was calculated, and the results indicated that pictorial recall was significantly better than phrase recall $[\mathrm{A}(29)=.115$, $\mathrm{p}<.01]$. Thus, the pictorial superiority hypothesis was supported, although the greatest picture-phrase differences were for emotional vs. nonemotional conditions (see Figure 1).

Two 2 by 2 ANOVA with repeated measures on both factors were computed to determine the effects of emotionality and relatedness on both picture and phrase recall. For phrase recall, the main effects of emotionality

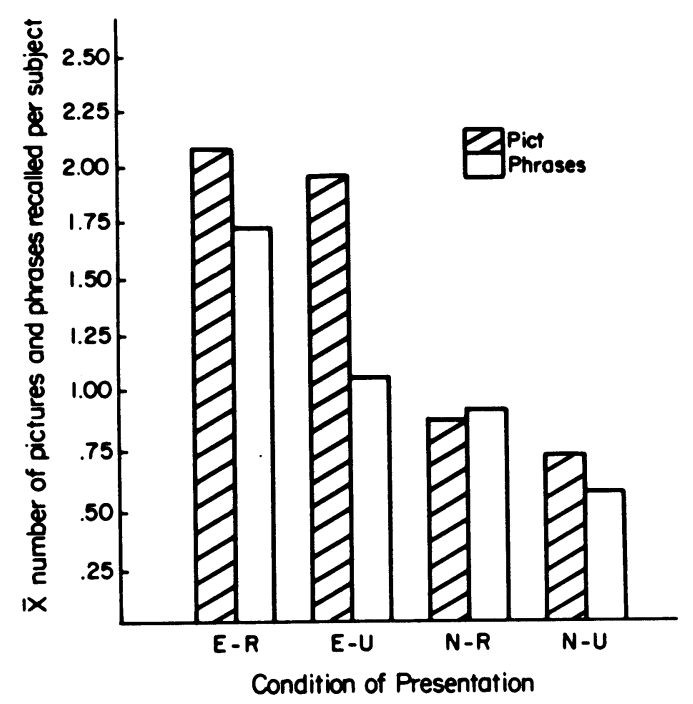

Figure 1. The mean number of items recalled under all conditions of presentation. and picture-phrase relatedness were both highly significant $[F(1,29)=25.48, p<.01$, and $F(1,29)=10.26$, $\mathrm{p}<.01$, respectively]. The interaction of Emotionality by Picture-Phrase Relatedness was not significant $[\mathrm{F}(1,29)=1.34$, n.s. $]$.

For picture recall, emotionality effects were large and even more significant $[F(1,29)=70.47, \mathrm{p}<.001]$, but the relatedness factor and the Emotionality by Relatedness interaction were not significant $[F(1,29)=$ 1.20 , and $\mathrm{F}(1,29)=.011$, respectively] .

Emotionality enhanced both picture and phrase recall, while picture-phrase relatedness enhanced only phrase recall. Phrase-recall results supported the encoding variability hypothesis in every respect. E-U and N-R phrases were recalled with approximately the same frequency; both were recalled significantly more than N-U phrases and less than E-R phrases. Thus, the hypothesis of one code for N-U phrases, two for E-U and N-R phrases, and three for E-R phrases was clearly supported. While other explanations of these data could no doubt be found, the extension of encoding variability to include an emotional code seems both appropriate and parsimonious.

Nelson and Reed's (1976) interpretation of pictorial superiority received indirect support here, for picturephrase relatedness did not affect picture recall significantly. The related conditions did produce slightly but not significantly better recall of pictures than the unrelated conditions (see Figure 1), which may indicate that some verbal cuing of picture recall occurred. But the recall procedure (phrases, then pictures) should have maximized verbal cuing of picture recall, and hence these data cannot be interpreted as lending any support to the dual-coding explanation of pictorial superiority. In conclusion, the manipulation of picture emotionality is a useful technique for evaluating the effects of emotionality on verbal and pictorial retention and should lend itself to the study of both individual differences and content variables in human memory.

\section{REFERENCES}

ABORN, M. The influence of experimentally induced failure on the retention of material acquired through set and incidental learning. Journal of Experimental Psychology, 1953, 45, 225-231.

BAHRICK, H. P., \& GHARRITY, K. Interaction among pictorial components in the recall of picture captions. Journal of Experimental Psychology: Human Learning and Memory, 1976, 2, 103-111.

CRAIK, F. I. M., \& LockharT, R. S. Levels of processing: A framework for memory research. Journal of Verbal Learning and Verbal Behavior, 1972, 11, 671-684.

Duffy, E. The psychological significance of the concept of "arousal" or "activation." Psychological Review, 1957, 64, 265-275.

ERICKson, M. H. Negation or reversal of legal testimony. American Medical Association of Neurology and Psychiatry, 1938, 40, 548-553.

Estes, W. K., \& DAPolito, F. Independent variation of information storage and retrieval processes in paired associate learning. Journal of Experimental Psychology, 1967, 75, 18-26. 
Holmes, D. S., \& Schallow, J. R. Reduced recall after ego-threat: Repression or response competition? Journal of Personality and Social Psychology, 1969, 13, 145-152.

KLUGMAN, S. F. Retention of affectively toned verbal material by normals and neurotics. Journal of Abnormal and Social Psychology, 1956, 53, 321-327.

KoEN, F. Polarization, $m$, and emotionality in words. Journal of Verbal Learning and Verbal Behavior, 1962, 1, 183-187.

Kотт, M. G. Learning and retention of words of sexual and nonsexual meaning. Journal of Abnormal and Social Psychology, $1955,50,378-382$.

Melton, A. W., \& Martin, E. (Eds.). Coding processes in human memory. Washington, D.C: Winston \& Sons, 1972.

MERRILL, R. M. The effects of pre-experimental anxiety on recall efficiency. Journal of Experimental Psychology, 1954, 48, 167-172.

Nelson, D. L., \& Reed, V. S. On the nature of pictorial encoding: A levels of processing analysis. Journal of Experimental Psychology: Human Learning and Memory, 1976, 2, 49-57.

Paivio, A. Imagery and verbal processes. New York: Holt, Rinehart, \& Winston, 1971.

Tzeng, O. J. L. Stimulus meaningfulness, encoding variability, and the spacing effect. Journal of Experimental Psychology, 1973, 99(No. 2), 162-166.
UNDERWOOD, B. J. Experimental Psychology (2nd Ed.). New York: Appleton-Century-Crofts, 1966.

WeIner, B. Motivation and memory. Psychological Monographs: General and Applied, 1966, 80, p. 22.

Zeller, A. F. An experimental analogue of repression. II. The effect of individual failure and success on memory measured by relearning. Journal of Experimental Psychology, 1950, 40, 411-422.

\section{NOTE}

1. Since the Bahrick and Gharrity (1976) study showed that picture recall cues phrase recall, subjects were instructed to recall phrases before they were asked to recall pictures. That is, we attempted to avoid pictorial cuing of phrases while maximizing the possibility of phrase recall cuing picture recall, so as to have a sensitive measure of any verbal coding of pictures which may have occurred.

(Received for publication October 11, 1977.) 